\title{
Article
}

\section{"Gymmy": Designing and Testing a Robot for Physical and Cognitive Training of Older Adults}

\author{
Maya Krakovski ${ }^{1, *}$, Shikhar Kumar ${ }^{1}$, Shai Givati ${ }^{1}$, Moshe Bardea ${ }^{1}$, Oded Zafrani ${ }^{1}$, Galit Nimrod ${ }^{2}$, \\ Simona Bar-Haim ${ }^{3}$ and Yael Edan ${ }^{1}$ \\ 1 Department of Industrial Engineering and Management and ABC Robotics Initiative, \\ Ben-Gurion University of the Negev, Beer-Sheva 8410501, Israel; shikhar@post.bgu.ac.il (S.K.); \\ shaigiv@post.bgu.ac.il (S.G.); bardeam@bgu.ac.il (M.B.); odedzaf@post.bgu.ac.il (O.Z.); yael@bgu.ac.il (Y.E.) \\ 2 Department of Communication Studies and The Center for Multidisciplinary Research in Aging, \\ Ben-Gurion University of the Negev, Beer-Sheva 8410501, Israel; gnimrod@bgu.ac.il \\ 3 Physical Therapy Department, Ben-Gurion University of the Negev, Beer-Sheva 8410501, Israel; \\ barhaims@bgu.ac.il \\ * Correspondence: mayakrak@post.bgu.ac.il
}

Citation: Krakovski, M.; Kumar, S.; Givati, S.; Bardea, M.; Zafrani, O.; Nimrod, G.; Bar-Haim, S.; Edan, Y. "Gymmy": Designing and Testing a Robot for Physical and Cognitive Training of Older Adults. Appl. Sci. 2021, 11, 6431. https://doi.org/ 10.3390/app11146431

Academic Editor: Ioannis Kostavelis

Received: 31 May 2021

Accepted: 7 July 2021

Published: 12 July 2021

Publisher's Note: MDPI stays neutral with regard to jurisdictional claims in published maps and institutional affiliations.

Copyright: (c) 2021 by the authors. Licensee MDPI, Basel, Switzerland. This article is an open access article distributed under the terms and conditions of the Creative Commons Attribution (CC BY) license (https:// creativecommons.org/licenses/by/ $4.0 /)$.

\begin{abstract}
Physical and cognitive training can maintain and improve older adults' independence and quality of life. Given the demographic growth of the older adult population and the shortage of caregivers, there is a need for personal trainers for physical and cognitive activities. This study suggests that social robots can satisfy this demand and presents the development of "Gymmy", a robotic system for the physical and cognitive training of older adults. The system design includes a humanoid mechanical-looking robot to demonstrate exercises, an RGB-Depth (RGB-D) camera to measure performance and a touch screen and speakers to provide instructions and feedback. Experiments with 26 older adults (65-84 years of age) were performed in home environments to examine the effect of users' characteristics (age, gender, education and attitude toward robots), the addition of cognitive training and the success rate of the acceptability of a robot trainer. The results showed that age, attitude and education influenced the acceptance of the robotic system. The findings highlight the importance of customizing the system to the needs of different users and the role of meaningful feedback. The system was proven to be robust and reliable, demonstrating clear potential to be used as a personal trainer and as a means of motivating older adults.
\end{abstract}

Keywords: robotic trainer; older adults; human-robot interaction; technology acceptance; assistive robot; social robot

\section{Introduction}

The effect of aging on cognitive and physical performance has been studied extensively. Cognitive functions, which involve decision-making, problem-solving, planning, multitasking, processing speed and working memory, are known to decline with age [1] There is a relatively steady rate of decline from early adulthood onward, but the decline accelerates when people approach old age [2]. There is a similar decline among the elderly in physical performance, muscle mass, strength and power [3,4]. Sarcopenia-muscle-mass decline due to reduced skeletal muscle mass-is one of the critical risk factors in the wellbeing of older people [5], and loss of strength in the upper extremities is a crucial factor in functional dependency [6]. These changes in both mental and physical performance are underpinned by a deterioration in the structure and function of the body's physiological systems $[3,7,8]$.

Given the adverse effects of aging, it follows that the significant demographic growth in the world's elderly population has brought about a substantial increase in the social burden of physical and cognitive disability. The parallel global shortage of caregivers and nurses means that healthcare systems for older people have been placed under unprecedented strain [9-11]. 
The term "older adults" refers to people aged above 65 years and includes three subsets [12]: "younger-old" (65-74 years), "old-old" (75-84 years) and "oldest old" (85+ years). Within all three groups, regular physical activity, or even occasional exercise, can reduce the development of physical and cognitive disability, the risk of depression and the incidence of various physical diseases such as stroke and cancer. It follows that such interventions can also reduce mortality rates [13]. Similarly, cognitive training can improve functions such as memory, attention and processing speed [14-16]. It is therefore recognized that these two forms of training can minimize the need for medical care and that they are a critical means of increasing older adults' quality of life and maintaining their independence $[14,17]$. Furthermore, the evidence suggests that a combination of cognitive training and physical training produces better effects than each type of training used independently $[18,19]$. This combination is particularly effective when directed at memory and attention [20,21]. Given the absence of pharmacological solutions to prevent cognitive decline, the use of such cognitive training has emerged as a valuable alternative.

Despite the demonstrable health benefits of physical and cognitive training, many people lack access to suitable programs or the motivation to pursue them. In 2019, for example, only $12 \%$ of the US population above 65 undertook the recommended amount of physical activity [12]. The explanation for such low levels of engagement in physical activity has been investigated by psychologists and researchers in the area of sport and exercise [22] Levels of motivation for physical exercise were found to vary between individuals as a function of their gender and their perceptions of the importance of maintaining health [23]. There are also various factors (such as time, cost and personal priorities) that make it difficult for people to undertake regular exercise. It seems, therefore, that the role of human motivation in engagement in physical activity is significant [24].

Access to training is an additional factor. Since older adults prefer "aging in place" but may also experience mobility difficulties, they may find it hard to independently access facilities such as gyms, studios and country clubs. Personal trainers are a potential solution for such problems, and they have been found to increase motivation to perform physical activities $[22,24]$. However, such trainers have become a scarce resource and are not always available at the required time and place [25-27].

It has been shown that social robots can improve the quality of older adults' lives and compensate for the shortage of caregivers and personal trainers [28,29]. Social assistive robots are advancing in many daily living applications for older adults [30-34], such as service robots which detect risks (such as in [35]), emergencies [36] and daily behaviors [37], offer medicine reminders [35], follow the user [38], assist with cooking [35,39], setting the table [40], cleaning [41], dressing [42,43] and feeding [44,45] and companionship [46,47].

In contrast to a human trainer, a robotic trainer is more flexible in terms of location and availability over time [26]. Studies show that people in general, and older adults in particular, prefer a physical robot over a virtual agent as an exercise trainer; they rate their interactions with physical robots as more engaging and more enjoyable and consider the trainers themselves to be more effective than virtual agents [28,48]. Similarly, for cognitive training, research shows that robots can be used to improve cognition [27,49], although there are cheaper alternatives such as computer and mobile phone applications. However, social robots add value due to their multi-functionality (for example, combining physical and cognitive training [50]) and their novelty as a means of interaction. This feature itself can stimulate brain activity [27].

In designing social robotic systems, the incorporation of a capacity to motivate users improves the quality and effectiveness of human-robot interaction [51]. In addition, research suggests that theory-based interventions can increase physical activity by $10-15 \%$ compared with structured exercise training [52]. In keeping with these observations, a meta-analysis of interventions to promote physical activity [53] revealed that theory-based interventions have a larger effect on physical performance than interventions that are not based on a theory, while the effect of motivational interventions is on the willingness to take up a physical activity. 
Different motivational theories such as "flow theory" [54] and "self-determination theory" (SDT) [55] have been applied to the design of technological interventions to encourage physical activity. Flow theory can be applied to a situation in which people are fully invested in an activity and likely to ignore other possible calls on their attention. This is likely to occur under three conditions: (1) where the system has a clear set of goals, (2) where the user can obtain clear and instant feedback and (3) where the demands of the intervention match the skills of the user. Approaches based on flow theory link enjoyment to motivation, and they have been applied in exergames [23]. These observations recommend that integrating fun and exercise can enhance enjoyment and lead people to be more motivated to engage in physical activity. SDT-inspired interventions [22] are focused on three psychological needs that are presumed to provide the basis of human motivation: relatedness, competence and autonomy. When the activity supports the user's autonomy and self-determination, it increases intrinsic motivation, which positively affects adherence to an exercise regime and to long-term behavior change.

Two studies presented their own design methodology for a robotic trainer that will increase motivation for physical activity based on SDT and flow theory principles $[28,56]$. Those principles include the provision of positive feedback, the avoidance of negative feedback, matching the nature of the interaction to the characteristics of the user and offering a range of challenging activities and exercise games with a variety of difficulty levels. Furthermore, this approach focuses on the fluidity of the interaction in order to avoid boredom and frustration among users. Both SDT and flow theory emphasize the importance of clear and instant feedback for the maintenance of motivation. In our previous work with a robotic physical training system [57], it was found that continuous feedback is the preferred mode and that visual and audio feedback should be combined. This previous work also compared two types of robots, a toy-like robot (Nao) and a more mechanical-looking robot (Poppy). Older adults preferred the mechanical-looking version. This preference probably resulted from a perception of the mechanical look being more suitable for a robotic trainer than a toy-like look with a gaming attraction.

Technologies for older adults need to take into account the significant differences between individuals within that sector of the population [30]. Although the previously cited research was intended to generate dedicated designs for older adults, it was not sensitive to variations in individual characteristics associated with age, gender, education and attitudes toward robots. For example, it is known that younger older adults are more open to technological change and express greater willingness to use robots than older ones $[58,59]$. Gender differences were also found; it is suggested that since men tend to have more experience with technology than women they adjust more easily to the use of robots [58]. Research on human-like assistive robots [60] found that there were fewer negative attitudes toward robots among those with higher education, and there was also a positive correlation between concern about cognitive decline and the willingness to accept cognitive support from robots.

The present study is intended to evaluate and develop a robotic physical and cognitive training system for long-term use. It is based on previous research that determined the type of robot and feedback system preferred by older adults [57]. Using the results and recommendations provided in our previous research, the new system was enhanced with Intel's D435 camera, a larger variety of physical training exercises (doubled from the original set), an improved graphical user interface and a more robust system design, enabling it to be used in different environments and by older adults without external guidance. Moreover, cognitive training was added to enhance the beneficial effects of the training. The specific objectives were the following:

(a) Develop an advanced physical training robotic system that also includes cognitive training;

(b) Evaluate how acceptance of the technology is influenced by individual characteristics (e.g., age and gender) and by success during training (i.e., how does success in specific exercises influence the acceptability of the technology as a whole?); 
(c) Compare acceptance of a robotic trainer that offers physical training only with one that combines physical and cognitive training.

The system was designed to be compact, robust, easy to use and enable long-term independent operation by older adults in their homes.

\section{System Development}

\subsection{System Description}

The system (Figure 1) comprised a computer system with an integrated humanoid mechanical-looking robot (Poppy Torso) to demonstrate the exercises and an RGB-D (depth) camera to monitor the user's performance (Realsense D435). The robot operated as a robotic physical coach with the capacity to demonstrate physical activity; hence, it was named "Gymmy" to elicit the connotations of the word "gym". The robot was equipped with a touch screen instead of the original head, which served the dual purpose of providing visual feedback and delivering cognitive training exercises. Speakers were installed to offer instructions and verbal feedback. Parallel programming was used to implement the system's algorithm and integrate the robot, camera, audio and screen functions.

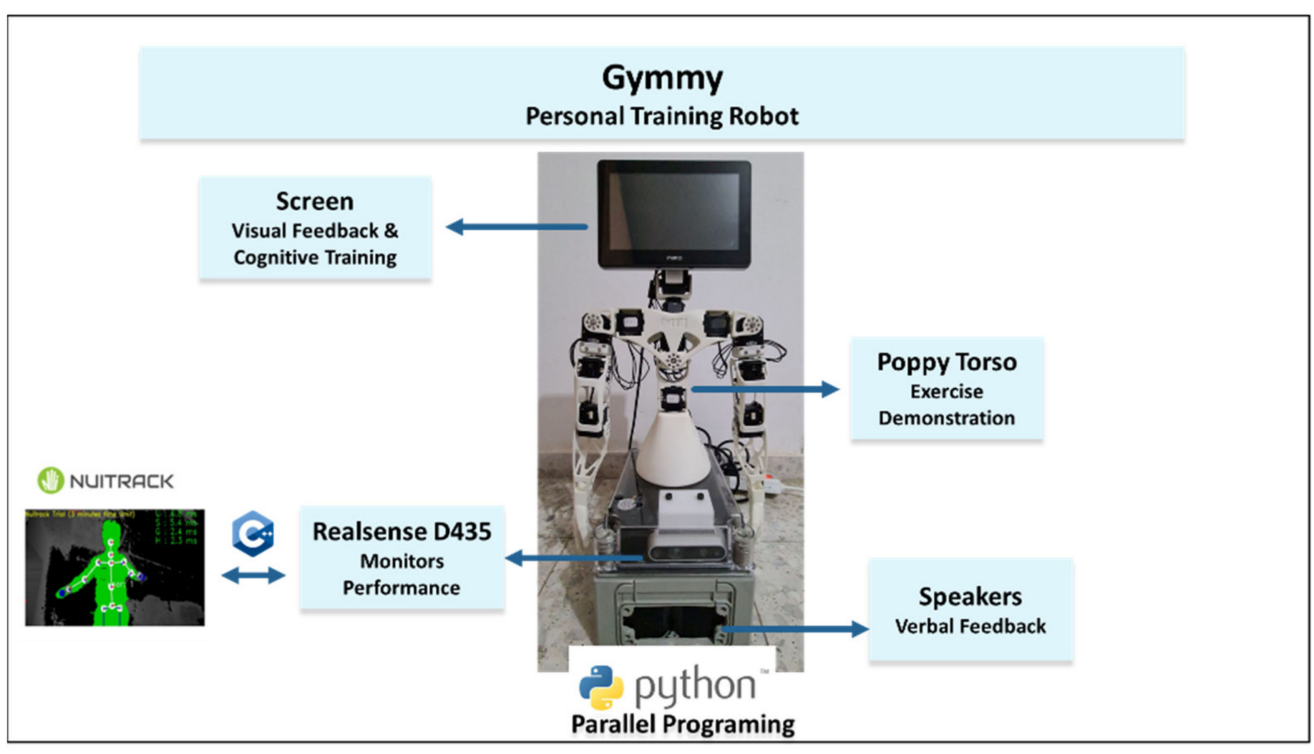

Figure 1. System description.

\subsection{Hardware}

The system included the following (Figure 2):

- Poppy torso robot: Poppy is an open-source, 3D-printed humanoid robot. Its height is $84 \mathrm{~cm}$ and its weight is $3.5 \mathrm{~kg}$ [61]. Poppy was designed to be anthropomorphic with 25 degrees of freedom (DOF), including a 5-DOF articulated trunk [62]. This project used only the torso part of the Poppy humanoid.

- Realsense D435 Camera: An RGB depth camera by Intel measuring $90 \mathrm{~mm} \times 25 \mathrm{~mm} \times 25 \mathrm{~mm}$ was connected via USB 3. The RGB frame resolution was $1920 \times 1080$, and the depth output resolution was up to $1280 \times 720$.

- Touch screen: The original head was replaced by a 7-inch multitouch screen that was attached to the head motor with a component that was created by a 3D printer. This change was made in order to provide a bigger screen than the original, which was considered important for older adults. This also permitted the display of more information on the screen.

- The following system components were fitted inside a dedicated box:

- $\quad$ Nuc mini PC: A small Intel PC with an Intel ${ }^{\circledR}$ Core $^{\mathrm{TM}}$ i5-8259U processor $(2.30 \mathrm{GHz})$ was the core of the system and was connected to all system components via USB. 
- Speakers: The speakers were placed in the front part of a dedicated box with a modified opening so that the audio signal could be easily heard.

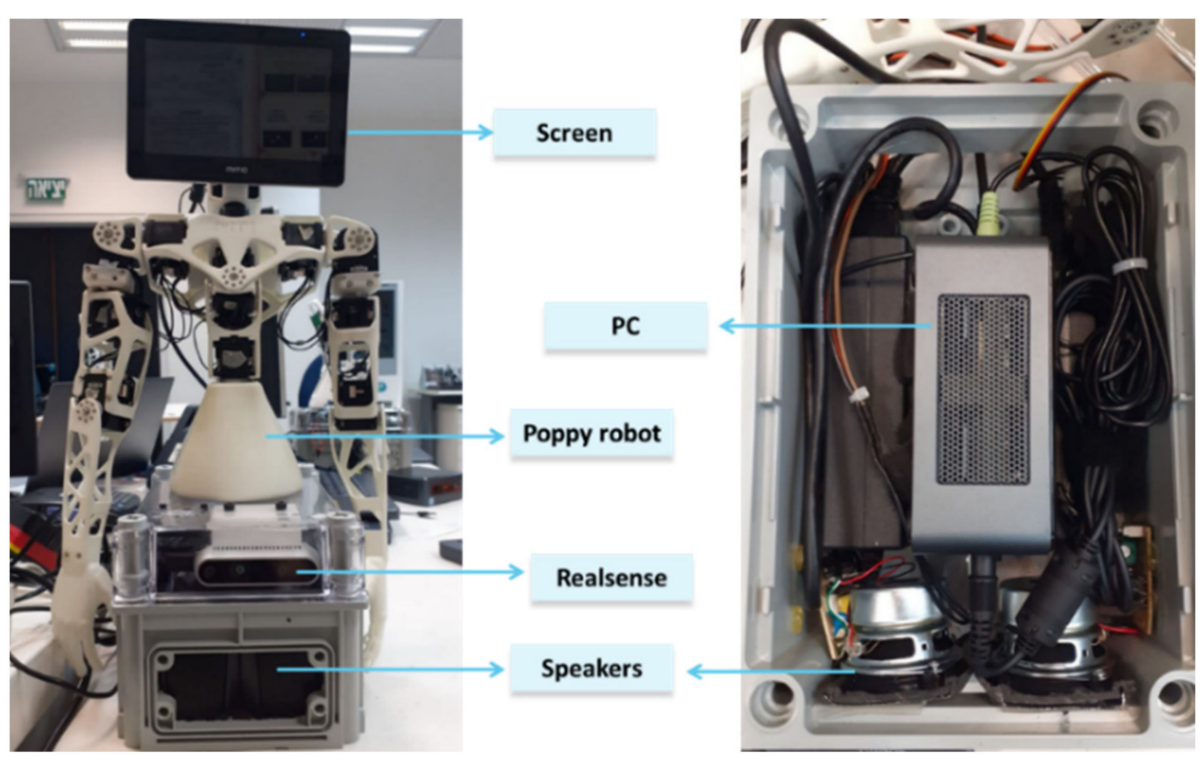

Figure 2. The developed system hardware.

As one of the development goals was to enable self-use by older adults, the power cord of the system was equipped with a switch to easily turn on or off the system, allowing the user to activate the system with one touch.

Intensive trials of the reliability of the system were performed for several hours by allowing it to operate in an infinite loop through the full range of exercises.

\subsection{Software}

A Realsense D435 RGB-D camera was employed to monitor user performance during the exercise sessions. Using Nuitrack software (https: / / nuitrack.com/ retrieved 1 July 2019), which was selected based on its accurate performance [63], the system performed skeleton tracking to determine the user's movements. The software tracked the positions of 19 human joints using three coordinates for each position: $\mathrm{x}, \mathrm{y}$ and $\mathrm{z}$ (lateral position, height and depth, respectively). The data on the positions of the joints were sent to the main Python script from a C++ script via client-server communication. Using the positional data, an algorithm was developed to check whether the user made the correct movement based on equations representing the distance and angle. Feedback (visual and auditory) was provided to encourage improved performance in light of the user's actual movement data. The logical sequence of actions and decisions is represented in the flowchart shown in Figure 3. 


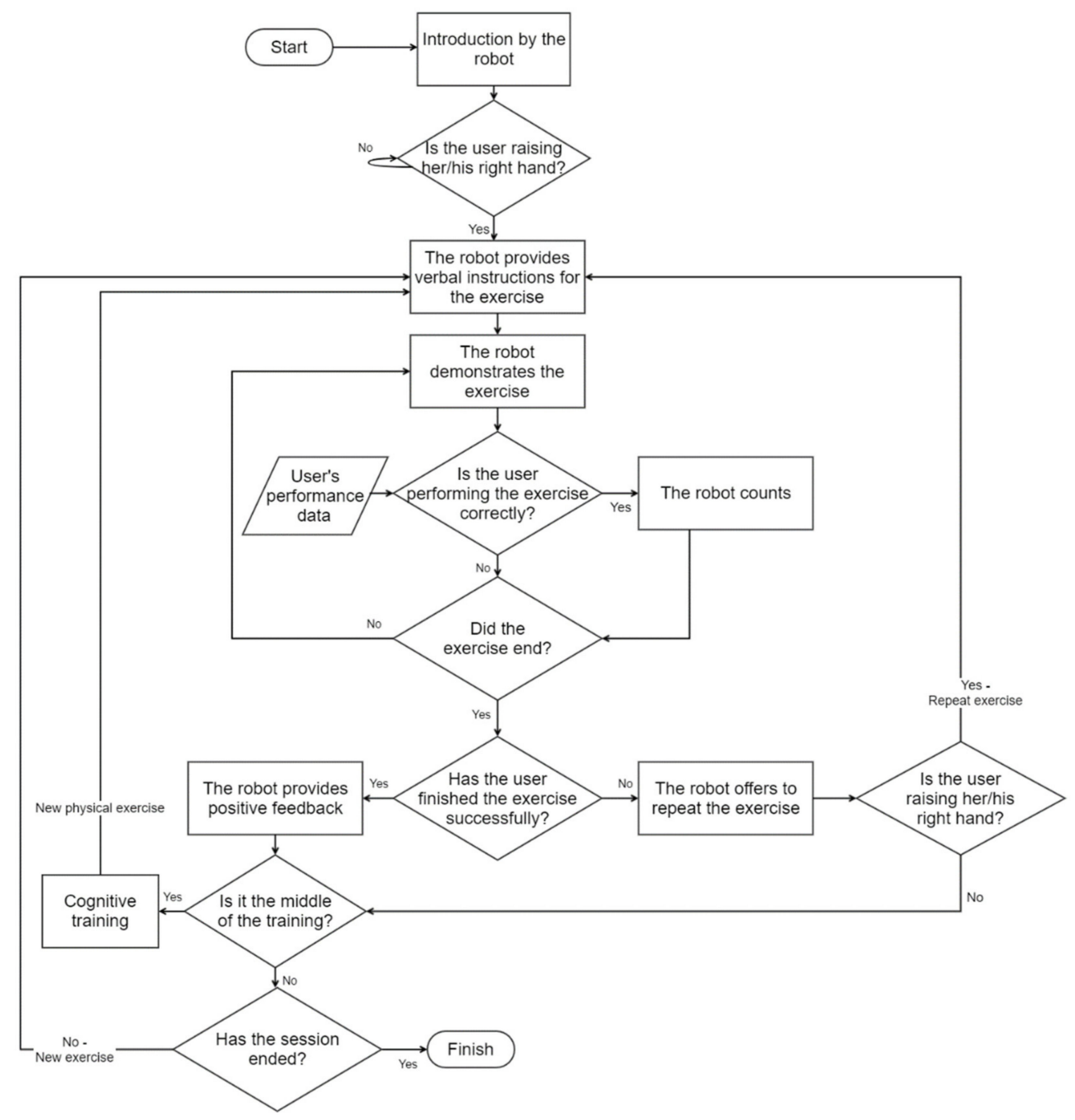

Figure 3. Flowchart of logical processes in the training system.

\subsection{Development of Physical Exercises}

The system's physical training focus was on strength exercises for the upper body to avoid balancing challenges among older users. This was incorporated in the functionality of the Poppy robot's torso version. These exercises improve muscle strength by building muscle and preventing the loss of bone mass. Together, these outcomes help older adults to maintain their independence and perform daily activities such as lifting objects or getting in and out of a car [64].

A total of 16 physical training exercises were developed according to the recommendations of the National Institute on Aging (NIH) (https:/ /go4life.nia.nih.gov/exercise-type/ strength/ retrieved 1 July 2019). Seven exercises were based on our previous work [48] (Figure 4), and nine new exercises were developed for the present study (Figure 5). 


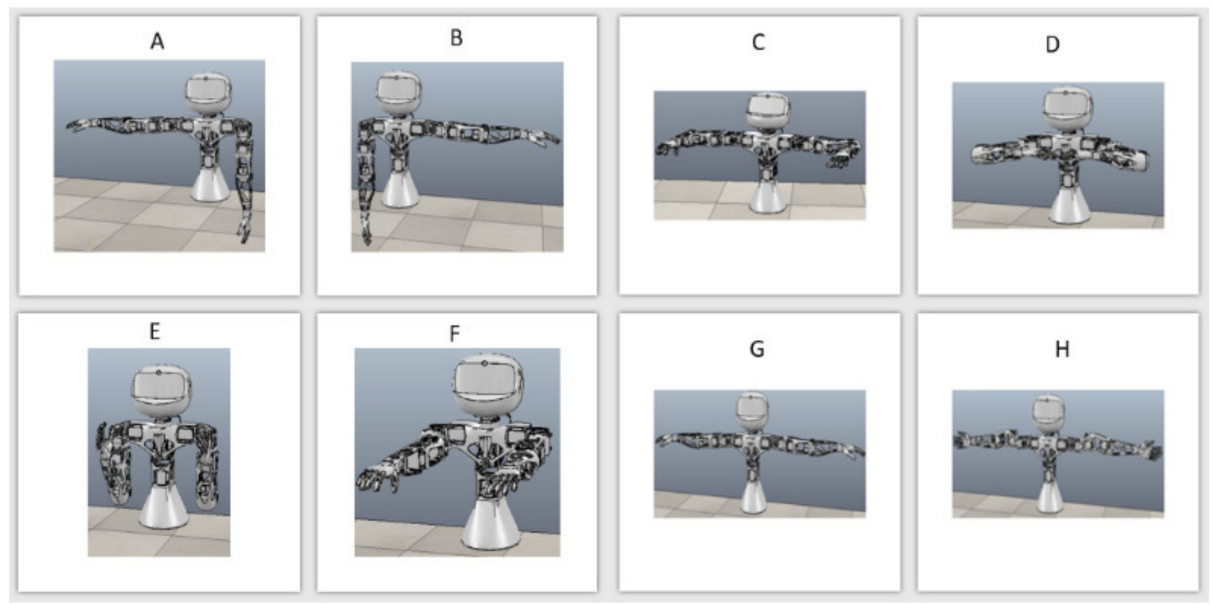

Figure 4. Original set of exercises: (A,B) — raise arms horizontally separately, (C) —raise arms and bend elbows forward 90, (D) —raise arms and bend elbows, (E) — bend elbows, (F)—raise arms forward static $(\mathbf{G})$ - raise arms horizon-tally, $(\mathbf{H})$-raise arms horizontally and turn hands.

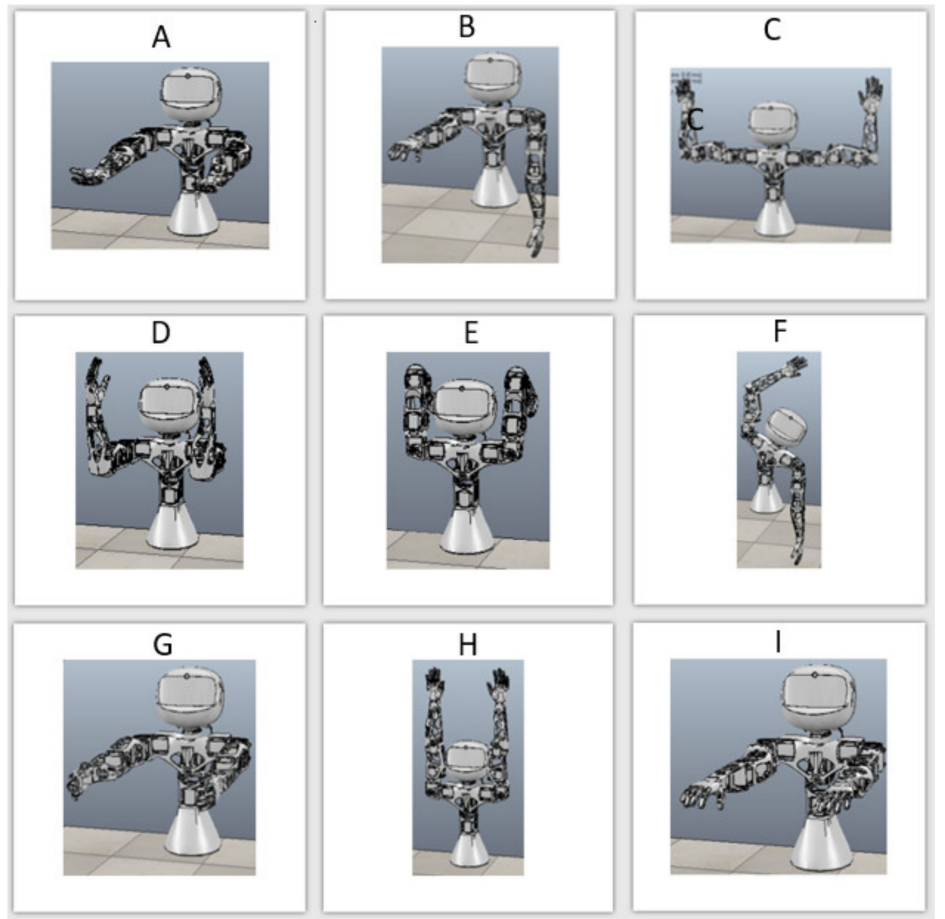

Figure 5. New set of exercises: (A) —raise arms forward and turn hands, (B) —raise arms forward separately, (C)—raise arms 90 and up, (D)_open and close arms 90, (E)-raise arms and fold backward, (F)—raise arms and lean (both sides), (G)—raise arms forward and to sides, $(\mathbf{H})$ _open hands horizontally and raise up, (I)—raise arms forward.

\subsection{Development of Cognitive Exercises}

The system's cognitive training was designed to address different aspects of memory and processing speed, which are known to decline with age and are essential for older adults' ability to live independently (e.g., taking medicine on time) $[18,20,65]$.

Three different cognitive games were integrated into the training sessions. The specific games were selected based on examples from the literature $[20,66,67]$ as detailed below. Each game started with instructions and then required users to signal their responses by using the touch screen when they were ready to do so. Feedback was provided at the end of 
each of the three rounds of each game. The games were inserted into the program between sets of physical exercises, with one game chosen randomly for each training session.

\subsubsection{Game 1: Working Memory}

This game, based on the work in [20], requires the user to remember the sequence in which words are highlighted on the screen. At the first stage, all the words are visible, but each one is highlighted in yellow for a few seconds in a particular order. The user must remember the order and, in the next stage, select the words in the order they were originally presented. The game screens are presented in Figure 6.

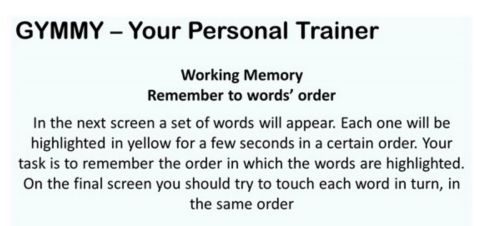

(a)

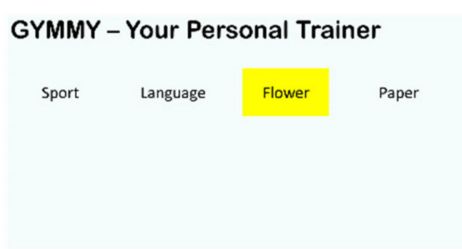

(b)

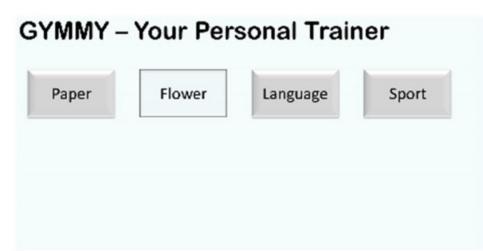

(c)

Figure 6. Cognitive game 1: (a) instructions screen, (b) words highlighted in a specific order and (c) the user attempts to choose the words in the same order.

\subsubsection{Game 2: Spatial Memory}

The goal of this game, inspired by the work in [66], is to remember a random spatial pattern that appears on the first screen. The pattern is defined by a subset of highlighted squares within a $5 \times 5$ matrix of squares. The pattern is highlighted for a few seconds, and the user is then required to recreate it on a blank $5 \times 5$ matrix. The game screens are presented in Figure 7.

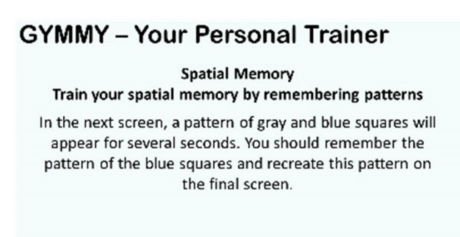

(a)

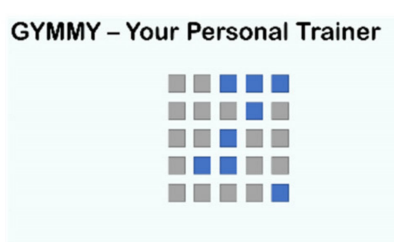

(b)

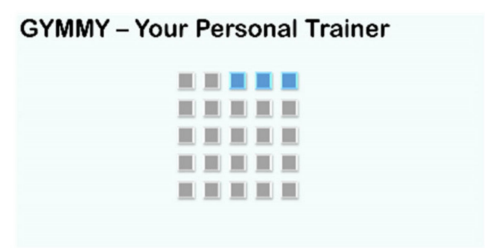

(c)

Figure 7. Cognitive game 2: (a) instructions screen, (b) a random pattern appears on screen and (c) the user attempts to recreate the pattern.

\subsubsection{Game 3: Mathematical Skills}

The aim of this game, inspired by the work in [67], is to solve simple mathematical equations that appear on the screen. A random mathematical equation appears on screen with four solution choices, and the user is required to select the correct solution. The game screens are presented in Figure 8.

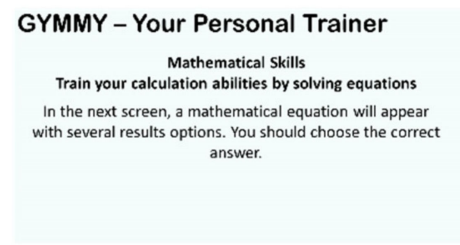

(a)

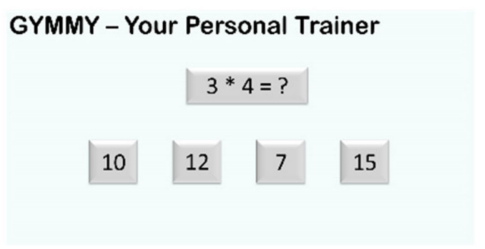

(b)

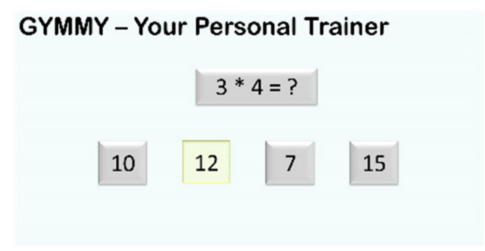

(c)

Figure 8. Cognitive game 3: (a) instructions screen, (b) the equation with solution choices appears on screen and (c) the user attempts to select the correct solution. 


\section{Methods}

User studies were conducted to examine the interaction of older adults with the robot and their acceptance of the new technology. We employed a "within subjects" experimental design in which the dependent variables were subjective measures related to the acceptance of the training, as assessed by means of questionnaires. The independent variables were the training type, either physical or combined (i.e., physical and cognitive), participant characteristics (age group, gender, education and negative attitude toward robots) and characteristics of the intervention (inclusion of cognitive training and success rates).

\subsection{Experimental Procedure}

Each participant underwent two training sessions: one included only physical training, and the other included both physical and cognitive training. The order of the sessions was randomized. After completing the consent form and pre-trial questionnaires, the user was asked to stand in front of the robot in order to start the session. Each session started with an introduction by the robot, and six physical exercises were randomly selected. For physical training, each session began with an explanation of how to perform the exercise, followed by a demonstration that was repeated eight times. During the demonstration, the user was required to follow the robot's demonstration and simultaneously perform the exercise. When the user correctly performed the required movement, the robot counted the repetition for the user. At the end of the demonstration, the robot provided feedback. If the user successfully performed eight repetitions of the required exercise in the demonstration time allocated, positive feedback was provided. Otherwise, the user was offered to try again, as described in Figure 3. The combined training session began with half of the required physical training exercises. This was then followed by the cognitive games and lastly by the remaining physical training exercises. For the cognitive training element, the robot asked the user to approach the robot's screen, and the cognitive game proceeded as described in Section 2.5. After each session, the user filled out a post-trial questionnaire.

\subsection{Participants}

Twenty-six older adults (17 females and 9 males) ages $65-84$ (mean $=73.54$, SD $=5.19)$ participated in the experiments. Sixteen of them belonged to the younger-old age group (11 females and 5 males; age: mean $=70.19, \mathrm{SD}=2.833$ ), and 10 belonged to the old-old age group ( 6 females and 4 males; age: mean $=78.9, \mathrm{SD}=3.07$ ). They were recruited through advertisements via different channels, including local senior centers, the university's Center for Digital Innovation, the university's retirees mailing list and by contacting older adults who had participated in former experiments that took place in our labs.

Due to COVID-19, older adults were understandably reluctant to come to the university to participate in the experiments. Therefore, the sessions took place in their own homes or at senior centers located in their vicinity. For each experiment, the robot was set up at the site. We arrived at the place, installed the system and monitored the experiments from a nearby room (in sight of the participant but without interfering with the experiments). All participants were healthy individuals who stated that they could perform basic physical activities such as standing and climbing stairs. Eighty percent $(21 / 26)$ indicated that they had high independence in performing household chores; the other $20 \%(5 / 26)$ reported moderate independence. Most of the participants had an academic degree: $30 \%(8 / 26)$ at bachelor's level and 30\% (8/26) at the postgraduate level. The remainder $(10 / 26)$ had high school or another level of education. All participants used technology regularly; they all had smartphones and computers. Sixty-nine percent $(18 / 26)$ of the participants used a computer every day, and 27\% (7/26) used one almost every day. However, most of the participants $(84 \%, 22 / 26)$ did not have previous experience with robots.

\subsection{Measures}

The pre-trial questionnaires aimed to assess demographic information (age, gender and education), technology usage and attitudes toward technology. The latter was mea- 
sured using the Negative Attitudes toward Robots Scale (NARS) (Table 1), which included three measures: S1 (negative attitudes toward situations and interactions with robots), S2 (negative attitudes toward the social influence of robots) and S3 (negative attitudes toward emotions in interactions with robots) [68]. The participants responded to the statements on a 5-point Likert scale, ranging from 1 ("strongly disagree") to 5 ("strongly agree").

Table 1. NARS.

\begin{tabular}{cr}
\hline & NARS \\
\hline S3 & I would feel relaxed talking with robots. \\
S2 & $\begin{array}{r}\text { I would feel uneasy if I were given a job where I had to use robots. } \\
\text { The idea that robots can make judgments about things excites me. } \\
\text { I would feel very nervous standing in front of a robot. }\end{array}$ \\
\hline S1 & I feel that if I depend on robots too much, something bad might happen. \\
\hline
\end{tabular}

The post-trial measures (which acted as the dependent variables) related to the perceived usefulness of the robot, its ease of use, the user's attitude (trust, enjoyment and satisfaction) toward it and the user's intention to use the system (Table 2), all of which were assessed by recording the level of agreement on a 5-point Likert scale, which for the analysis transformed to scale of "low" (1 or 2), "neutral" (3) and "high" (4 or 5). This questionnaire was developed and tested in our previous research [48]. We also used the physical activity enjoyment scale (PACES) [69] (Table 3) as a secondary measurement for enjoyment, which was assessed by a 7-point Likert scale. In addition to these subjective measures, the success rate in the physical exercises was measured by calculating the percentage of the successfully completed exercises. A success was defined as each exercise being performed correctly out of the eight repetitions.

Table 2. Post-trial questionnaires.

\begin{tabular}{|c|c|c|}
\hline \multicolumn{2}{|c|}{ Dependent Variable } & Measure \\
\hline \multicolumn{2}{|c|}{ Perceived Usefulness } & $\begin{array}{l}\text { I would be willing to train with the robot again } \\
\text { because it had value to me. }\end{array}$ \\
\hline \multirow{3}{*}{ Ease of Use } & Comfort & $\begin{array}{l}\text { I felt comfortable during the interaction. } \\
\text { I felt nervous during the activity. }\end{array}$ \\
\hline & Understanding & I understood the robot well during the interaction. \\
\hline & Effort & I put a lot of effort into this activity. \\
\hline \multirow{5}{*}{ Attitude } & Engagement & I concentrated on the activity for the entire session. \\
\hline & Trust & I felt like I could really trust this robot. \\
\hline & Satisfaction & $\begin{array}{l}\text { I was satisfied by the robot's performance } \\
\text { during this activity. }\end{array}$ \\
\hline & \multirow{2}{*}{ Enjoyment } & I enjoy exercising with the robot. \\
\hline & & PACES Questionnaire \\
\hline \multicolumn{2}{|c|}{ Intention to Use } & I would like to exercise with the robot in the future. \\
\hline \multicolumn{2}{|c|}{ Success Rate } & $\frac{\text { Number of success ful exercises }}{\text { Number of exercises }}$ \\
\hline
\end{tabular}


Table 3. Physical Activity Enjoyment Scale.

\begin{tabular}{cllllllll}
\hline & \multicolumn{7}{c}{ Physical Activity Enjoyment Scale } \\
\hline I find it pleasurable & 1 & 2 & 3 & 4 & 5 & 6 & 7 & I find it unpleasurable \\
It is no fun at all & 1 & 2 & 3 & 4 & 5 & 6 & 7 & It is a lot of fun \\
It is very pleasant & 1 & 2 & 3 & 4 & 5 & 6 & 7 & It is very unpleasant \\
It is very invigorating & 1 & 2 & 3 & 4 & 5 & 6 & 7 & It is not at all invigorating \\
It is very gratifying & 1 & 2 & 3 & 4 & 5 & 6 & 7 & It is not at all gratifying \\
It is very exhilarating & 1 & 2 & 3 & 4 & 5 & 6 & 7 & It is not at all exhilarating \\
It is not at all stimulating & 1 & 2 & 3 & 4 & 5 & 6 & 7 & It is very stimulating \\
It is very refreshing & 1 & 2 & 3 & 4 & 5 & 6 & 7 & It is not at all refreshing \\
\hline
\end{tabular}

\subsection{Analysis}

The theoretical model we used was the technology acceptance model (TAM) introduced by Davis in 1989 [70]. This theory models users' behavioral intentions to use technologies on the basis of their attitudes, which are affected by perceived usefulness and the ease of use of the device. Accordingly, the study examined how participant and intervention characteristics affected user's acceptance (Table 2). This was reported by percentages and by age group when relevant.

In addition to descriptive statistics, we undertook a regression analysis of the multivariate data using the $\mathrm{R}$ programming language with RStudio software. For each dependent variable (perceived usefulness, ease of use, attitude and intention to use), an ordinal regression with a cumulative link mixed model was fitted by order and backward regression. The random variable was the participant, and the independent variables were the type of training, age group, gender, education, session number, NARS questionnaire measures and the success rate in physical exercises. A likelihood ratio test (LRT) was used to compare the models, and the Spearman rank order correlation coefficient was computed to test for correlations between the ordinal variables.

\section{Results}

\subsection{Negative Attitude toward Robots}

Most participants (92.31\%) did not have negative feelings toward interaction with robots (NARS-S1) (low $=61.54 \%$, medium $=30.77 \%$ ). In terms of negative attitudes toward emotions during the interactions (NARS-S3), 90.00\% of the old-old age group (ages 75-84) had low negative feelings. The young-old age group yielded a more heterogeneous and negative response, with $50.00 \%$ having low negativity and $43.75 \%$ having medium negativity. When asked about the social influence of interactions with robots (NARS-S2), the responses of the age groups were as follows. Among the old-old group, $90.00 \%$ had low negativity, while among the young-old group, $37.5 \%$ had low negativity and $62.5 \%$ had medium negativity.

\subsection{Post-Trial Questionnaires \\ 4.2.1. Perceived Usefulness}

A substantial proportion of the participants $(46.15 \%)$ perceived the robotic physical training system as highly useful, while $30.77 \%$ were neutral regarding the robot's usefulness. The mean Likert score for this variable was 3.615 (SD =1.194). Regarding the different age groups, the majority $(60.00 \%)$ of the old-old age group rated the robot training as highly useful, in contrast to the young-old group which was more evenly distributed across the levels of usefulness. The best-fitting model for perceived usefulness was expressed as

Perceived Usefulness $\sim$ NARS_S1 + age_group + physical_success_rate + $(1$ I subject $)$

The model's results showed that the user's attitude toward interactions with robots (NARS-S1) had a significant association with their rating of perceived usefulness; a higher level of NARS-S1 (implying greater negativity) resulted in lower ratings of perceived usefulness in comparison with the lower level (S1-medium $p=0.00432$, S1-high $p=0.01767$ ). In 
addition, in line with the descriptive statistics, being in the old-old group had a significant positive association with perceived usefulness $(p=0.01493)$. The success rate in the physical exercises had a positive association with the perceived usefulness; users that had higher success rates rated the perceived usefulness higher $(p=0.02443)$.

\subsubsection{Ease of Use}

Three aspects of ease of use were explored by the questionnaires-: comfort, understanding and effort. The vast majority of the participants (88.46\%) felt comfortable interacting with the robotic system (mean Likert score $=4.577, \mathrm{SD}=0.6433$ ). Most of them $(65.38 \%)$ also felt that they understood the robotic system well, while $26.92 \%$ were neutral on this measure (mean Likert score $=4.154, \mathrm{SD}=0.914$ ). Similarly, most participants $(84.61 \%)$ indicated that they invested low effort in the training with the robotic physical trainer (mean Likert score $=1.788, \mathrm{SD}=0.992$ ). There was no significant correlation between the independent variables and the effort rating; therefore, the ease of use measure was calculated as an average of comfort and understanding. The best-fitting model for ease of use was expressed as

Ease of use $\sim$ education + age_group + NARS_S1 + NARS_S2 + NARS_S3 + (1 | subject $)$

All of the NARS components showed a significant association with the ease of use rating. The medium levels of NARS-S1 and NARS-S2 resulted in lower ratings for the ease of use than the low levels (NARS-S1 $p=0.005$, NARS-S2 $p=0.024$ ). NARS-S3, which represents negative feelings about interactions with robots, also showed a significant association: participants with medium negativity rated the ease of use more highly than persons with low negativity $(p=0.0201)$. Regarding the level of education, compared with the base level (high school education), people with their first degrees rated the ease of use lower $(p=0.027)$, while people with postgraduate degrees rated it higher $(p=0.008)$. The age group variable also contributed to the model's goodness of fit, with the old-old age group giving higher ease of use ratings, although it is worth noting that this relationship did not reach significance $(p=0.077)$.

\subsubsection{Attitude}

The participants' attitudes were measured by four variables that were combined into a single measure (attitude) for modeling purposes: engagement, trust, satisfaction and enjoyment. Most participants $(80.77 \%)$ gave high ratings of engagement with the robotic physical trainer (mean Likert score $=4.212$, SD $=0.874$ ). Similarly, the majority $(65.38 \%$ ) expressed trust in the trainer (mean Likert score $=3.865, \mathrm{SD}=0.975)$. Half of the participants reported high satisfaction, and 30.77\% were neutral (mean Likert score $=3.615$, $\mathrm{SD}=1.042)$. The majority $(61.54 \%)$ agreed with the statement that they enjoyed the robotic training session, while $26.92 \%$ were neutral (mean Likert score $=3.942, \mathrm{SD}=0.931$ ). The PACE questionnaire generated similar results; $30.77 \%$ yielded a high enjoyment score (6 or 7 ), and $65.38 \%$ reported a moderate enjoyment score $(3,4$ or 5$)$ (mean $=4.827, \mathrm{SD}=1.288)$.

Turning to the combined attitude measure, the best-fitting model was expressed as

$$
\text { Attitude } \sim \text { physical_success_rate }+(1 \text { | subject })
$$

Thus, the success rate in the physical exercises was the only variable that was significantly predictive of the participants' attitudes toward the robot training system. Unsurprisingly, higher levels of success resulted in higher attitude ratings $(p=0.019)$.

\subsubsection{Intention to Use}

About half of the participants (46.15\%) indicated a clear (i.e., rating of 4 or 5 ) intention to use the robotic system in the future, and $26.92 \%$ were neutral (mean Likert score $=3.5$, $\mathrm{SD}=1.257)$. There was greater commitment to using the system in the old-old group $(60 \%$ 
yielded a rating of 4 or 5), whereas the young-old adults were more evenly distributed across the scale. The best-fitting model for intention to use was expressed as

$$
\text { Intention to use } \sim \text { age_group + NARS_S1 + (1 I subject })
$$

In line with the descriptive statistics, the model showed that the intention to use was positively associated with being in the old-old group; however, it was not significant $(p=0.1)$. Furthermore, the NARS-S1 rating had a significant negative association with the intention to use (medium $p=0.019$, high $p=0.022$ ).

\subsection{Technology Acceptance Model Relationships}

The final stage of the analysis was to test the existence of the relationships between the original components of the TAM: the intention to use with attitude and attitude with the perceived usefulness and ease of use.

First, the level of correlation was calculated between the perceived usefulness and ease of use to the overall attitude measure separately. Spearman's rank correlation revealed a positive correlation between the attitude and perceived usefulness ( $\rho=0.406, p=0.003$ ) as well as between the attitude and ease of use $(\rho=0.347, p=0.012)$. We also examined if a complex model that included these variables could better explain the data when compared with the simple model (Equation (3)). This indeed revealed that the complex model was significantly better at explaining the attitude variable $(p=0.001)$.

Secondly, the level of correlation was calculated between the attitude and intention to use. The Spearman rank order correlation coefficient between these two variables was $\rho=0.355(p=0.010)$. However, an LRT test to include the attitudinal variable in the intention to use model (Equation (4)) was not significant $(p=0.312)$. However, in this test, the convergence criterion was not met for the model. This may occur when the variables are linear functions of each other or when the sample is small or unduly constrained in terms of certain values.

Based on the above analysis of the various predictor variables, Figure 9 presents a conceptual model of attitudes to robotic training and the intention to use the system.

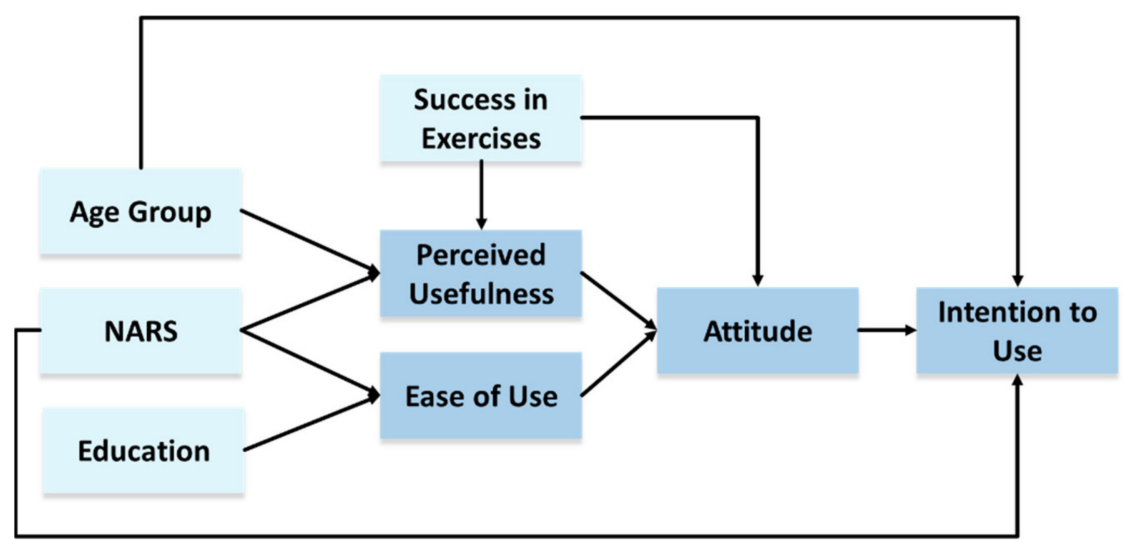

Figure 9. Technology acceptance conceptual model of a physical and cognitive robotic trainer.

\section{Discussion}

The findings revealed that the age group, negative attitude toward robots and education were individual characteristics that associated with the acceptance of the robotic system. Gender did not have a significant effect on any of the TAM components.

The old-old group perceived the robotic trainer as significantly more useful than the younger-old group. The old-old group rated the robot's ease of use higher than the younger-old group and also yielded a higher score for the intention to use, but the differences were not significant. These trends do not conform with previous studies, which found that older adults in the younger age group expressed greater intent to use robots 
than their old-old counterparts, probably because the former group is more technologically oriented $[58,59]$. However, our findings may suggest that old-old adults have a greater need for the developed robotic system; therefore, they perceive it as more useful. Several younger participants noted in informal conversation after the experiment that they thought the experience with the robotic system was pleasant, but because they were physically active, the exercises provided by the system were not challenging for them. They believed the robot could benefit people who were less active or older. Accordingly, when designing a robotic system for older adults, it is clearly important to customize the system to the specific user needs and especially to ensure that the exercise difficulty matches (or slightly exceeds) the user's capability.

The effects of education and negative attitudes toward robots corresponded to those observed in previous works. Graduate degrees had a positive association with the ease of use compared with high school education, resembling the findings on the acceptance of smartphones among older adults [71]. However, having an undergraduate degree resulted in a lower ranking for the ease of use in our analysis. This should be tested with a larger participant sample size in order to achieve clearer results. The negative attitude toward robots ranking was also found to have a significant association with the system's acceptability. For example, a negative attitude was found to have a negative correlation with the perceived usefulness of assistive and companion robots in a survey among older adults [72]. In our analysis, gender was not found to be associated with acceptability. This might be explained by the participants' familiarity with technology, which was similar for both genders in the present study, in contrast to other studies that did demonstrate a gender effect [58].

Although several participants expressed satisfaction with the cognitive training and recognized its importance, the inclusion of such training within the session did not have a significant effect on acceptability as it was not found to be included in any of the best or final regression models. This might be explained by the relative lack of complexity of the cognitive training or by the difficulty in discriminating between the two types of training sessions, meaning the participants did not experience much difference between the two types of sessions and thus did not express a different opinion following them. Subject to further analysis, the implication would seem to be that more complex cognitive training games are required and that they should form a more intrinsic part of the training. Another issue that was raised by the participants was that the insertion of cognitive training in the middle of the physical training was problematic and confusing. A possible solution might be to separate the two types of training. However, this would work against the notion of making the cognitive work intrinsic to the program and the notion that practice variability is actually necessary for skill improvement. Furthermore, as the random ordering of training seems to support retention, complete separation of the cognitive and physical components might impede generalization to other sequential behaviors [73]. This should be tested in future system design research.

The success rate in the physical exercises appeared to be a significant variable in the TAM model, having a positive association with both the perceived usefulness and the combined attitude measure. In our system, exercise success is signaled to the user by the system's feedback mechanism. When the user performs the movement correctly, the robot signals a correct repetition with verbal feedback and delivers a positive comment (such as "well done") after eight successful repetitions. These results suggest the importance of feedback in robotic training systems. They are consistent with flow theory and SDT, both of which emphasize the link between feedback and motivation to engage. We posit that this relationship is underpinned by perceptions that the robot is useful, reliable, comprehensible and, by positive feelings, associated with success.

The resultant conceptual model (Figure 9) suggests the users and interaction characteristics that can influence the acceptance of a robotic trainer by older adults. This model is based on a relativity small sample due to the circumstances of the COVID-19 pandemic, 
which raised difficulties in recruiting older participants. Future studies should investigate this model with a larger sample to verify our results.

Apart from the findings relating to the predictor variables, the robot training system was shown to be robust and reliable outside of the laboratory. It proved possible to conduct the experiments in real-life environments, either in the participants' homes or in older adults' clubs. There were no malfunctions in any of the experiments. Additionally, the system was also installed successfully in different places and worked well with no failures for an extended period of time (Four robotic systems were installed as part of another research project and were operated independently in 16 older adults' homes. In an accumulated period of 98 weeks, there was only one failure in one motor, implying a 1.02\% failure rate).

\section{Conclusions}

Overall, the system appears to have potential for use as a personal trainer and as a means of motivating older adults to undertake physical and cognitive activity at home, thereby improving their quality of life. Most users were satisfied with the robot's performance; they enjoyed the training sessions and perceived the system as easy to use and useful. Many of them also indicated a clear willingness to use the system in the future. The successful users' experiences with the system demonstrated the reliability and robustness of the system in different environments.

This research also revealed the importance of customizing the system to meet the needs of different users, since these needs clearly vary across different age groups. It also pointed to the importance of providing meaningful feedback, especially in relation to failed exercises. Therefore, our future program will seek to enhance the system via more specific feedback to improve the quality of the human-robot interaction and increase its acceptability among older adults.

Overall, this study offers design recommendations to improve the interaction with a robotic trainer, which is also relevant to the design of assistive robots in general [29]. These insights could be implemented in the design of physiotherapy and rehabilitation robots in health care facilities and other social assistive robots intended to assist in daily life activities (such as person-following robots [38], assistance in table setting [74] or taking pills [75]) or robots that help cope with loneliness [76]). All of these applications need to adjust their designs to different characteristics of older adults in order to improve the interaction and usefulness of robotic systems.

The limitations of this work include the fact that only upper-body exercises were included in the system. There is a version of the full-body Poppy robot that could be used for this purpose, but this approach might prove to be contraindicated for older adults due to balance problems, creating a risk of falling. Therefore, future research could also test sitting position exercises (for both the upper and lower body). This study is also limited by the absence of participants in the oldest-old group and by the sample size as discussed earlier. Future work should extend the investigation to this sector of the population and test the conceptual acceptance model on a larger sample.

Author Contributions: Conceptualization, M.K., Y.E. and S.B.-H.; methodology, M.K., Y.E. and S.B.-H.; hardware design, M.K., S.G., M.B. and Y.E.; software, M.K. and S.K.; data analysis, M.K.; interpretation of the data, M.K., S.K., S.G., M.B., O.Z., G.N., S.B.-H. and Y.E.; writing-original draft preparation, M.K.; writing—critical review and editing, M.K., S.K., S.G., M.B., O.Z., G.N., S.B.-H. and Y.E.; supervision, Y.E.; project administration, Y.E.; funding acquisition, Y.E., G.N. and S.B.-H. All authors have read and agreed to the published version of the manuscript.

Funding: This research was partially supported by the EU-funded Innovative Training Network (ITN) in the Marie Skodowska-Curie People Programme (Horizon2020): SOCRATES (Social Cognitive Robotics in a European Society training research network), grant agreement number 721619 and by Ben-Gurion University of the Negev through the Agricultural, Biological and Cognitive Robotics Initiative, the Marcus Endowment Fund, the Rabbi W. Gunther Plaut Chair in Manufacturing Engineering and by the Israeli Ministry of Science and Technology (grant number: 3-15713). 
Institutional Review Board Statement: This study was approved by the ethical committee of the Department of Industrial Engineering and Management at Ben-Gurion University of the Negev.

Informed Consent Statement: Informed consent was obtained from all subjects involved in the study.

Data Availability Statement: Data supporting the reported results can be found at https://github. com/MayaKrakovski/Gymmy_Data_Analysis (accessed on 12 July 2021).

Conflicts of Interest: The authors declare no conflict of interest.

\section{References}

1. Murman, D.L. The Impact of Age on Cognition. Semin. Hear. 2015, 36, 111-121. [CrossRef]

2. Christensen, H. What Cognitive Changes can be Expected with Normal Ageing? Aust. N. Z. J. Psychiatry 2001, 35, 768-775. [CrossRef] [PubMed]

3. Chodzko-Zajko, W.J.; Proctor, D.N.; Singh, M.A.F.; Minson, C.T.; Nigg, C.R.; Salem, G.J.; Skinner, J.S. Exercise and Physical Activity for Older Adults. Med. Sci. Sports Exerc. 2009, 41, 1510-1530. [CrossRef]

4. Trombetti, A.; Reid, K.F.; Hars, M.; Herrmann, F.; Pasha, E.P.; Phillips, E.M.; A Fielding, R. Age-associated declines in muscle mass, strength, power, and physical performance: Impact on fear of falling and quality of life. Osteoporos. Int. 2016, $27,463-471$. [CrossRef]

5. Morley, E.J. Sarcopenia in the elderly. Fam. Pract. 2012, 29, i44-i48. [CrossRef] [PubMed]

6. Williams, M.E.; Gaylord, S.A.; McGaghie, W.C. Timed Manual Performance in a Community Elderly Population. J. Am. Geriatr. Soc. 1990, 38, 1120-1126. [CrossRef]

7. Torpy, J.M.; Lynm, C.; Glass, R.M. Frailty in Older Adults. JAMA 2006, 296, 2280. [CrossRef] [PubMed]

8. Forman, D.E.; Berman, A.D.; McCabe, C.H.; Baim, D.S.; Wei, J.Y. PTCA in the Elderly: The 'Young-Old' versus the 'Old-Old,'. J. Am. Geriatr. Soc. 1992, 40, 19-22. [CrossRef]

9. Buerhaus, P.I. Current and Future State of the US Nursing Workforce. JAMA 2008, 300, 2422. [CrossRef]

10. Oulton, J.A. The Global Nursing Shortage: An Overview of Issues and Actions. Policy Politics Nurs. Pract. 2006, 7, 34S-39S. [CrossRef]

11. United Nations. World Population Prospects 2019, No. 141; United Nations: New York, NY, USA, 2019.

12. Czaja, S.J.; Boot, W.R.; Charness, N.; Rogers, W.A. Designing for Older Adults; CRC Press: Boca Raton, FL, USA, 2019.

13. World Health Organization. Global Recommendations on Physical Activity for Health; World Health Organization: Geneva, Switzerland, 2010; p. 60.

14. Mowszowski, L.; Lampit, A.; Walton, C.; Naismith, S. Strategy-Based Cognitive Training for Improving Executive Functions in Older Adults: A Systematic Review. Neuropsychol. Rev. 2016, 26, 252-270. [CrossRef] [PubMed]

15. Rebok, G.W.; Ball, K.K.; Guey, L.T.; Jones, R.; Kim, H.-Y.; King, J.W.; Marsiske, M.; Morris, J.N.; Tennstedt, S.L.; Unverzagt, F.W.; et al. Ten-Year Effects of the Advanced Cognitive Training for Independent and Vital Elderly Cognitive Training Trial on Cognition and Everyday Functioning in Older Adults. J. Am. Geriatr. Soc. 2014, 62, 16-24. [CrossRef]

16. Corbett, A.; Owen, A.; Hampshire, A.; Grahn, J.; Stenton, R.; Dajani, S.; Burns, A.; Howard, R.; Williams, N.; Williams, G.; et al. The Effect of an Online Cognitive Training Package in Healthy Older Adults: An Online Randomized Controlled Trial. J. Am. Med. Dir. Assoc. 2015, 16, 990-997. [CrossRef] [PubMed]

17. Matsusaka, Y.; Fujii, H.; Okano, T.; Hara, I. Health exercise demonstration robot TAIZO and effects of using voice command in robot-human collaborative demonstration. In Proceedings of the RO-MAN 2009-The 18th IEEE International Symposium on Robot and Human Interactive Communication, Toyama, Japan, 27 September-2 October 2009; pp. 472-477. [CrossRef]

18. Bamidis, P.; Vivas, A.; Styliadis, C.; Frantzidis, C.; Klados, M.; Schlee, W.; Siountas, A.; Papageorgiou, S. A review of physical and cognitive interventions in aging. Neurosci. Biobehav. Rev. 2014, 44, 206-220. [CrossRef] [PubMed]

19. Oswald, W.D.; Gunzelmann, T.; Rupprecht, R.; Hagen, B. Differential effects of single versus combined cognitive and physical training with older adults: The SimA study in a 5-year perspective. Eur. J. Ageing 2006, 3, 179-192. [CrossRef]

20. Eggenberger, P.; Schumacher, V.; Angst, M.; Theill, N.; de Bruin, E.D. Does multicomponent physical exercise with simultaneous cognitive training boost cognitive performance in older adults? A 6-month randomized controlled trial with a 1-year follow-up. Clin. Interv. Aging 2015, 10, 1335-1349. [CrossRef] [PubMed]

21. Lauenroth, A.; Ioannidis, A.E.; Teichmann, B. Influence of combined physical and cognitive training on cognition: A systematic review. BMC Geriatr. 2016, 16, 141. [CrossRef]

22. Patrick, H.; Canevello, A. Methodological overview of a self-determination theory-based computerized intervention to promote leisure-time physical activity. Psychol. Sport Exerc. 2011, 12, 13-19. [CrossRef]

23. Huang, H.-C.; Pham, T.T.L.; Wong, A.M.-K.; Chiu, H.-Y.; Yang, Y.-H.; Teng, C.-I. How to create flow experience in exergames? Perspective of flow theory. Telemat. Inform. 2018, 35, 1288-1296. [CrossRef]

24. Sussenbach, L.; Riether, N.; Schneider, S.; Berger, I.; Kummert, F.; Lutkebohle, I.; Pitsch, K. A robot as fitness companion: Towards an interactive action-based motivation model. In Proceedings of the 23rd IEEE International Symposium on Robot and Human Interactive Communication, Edinburgh, UK, 25-29 August 2014; pp. 286-293. 
25. Gadde, P.; Kharrazi, H.; Patel, H.; MacDorman, K.F. Toward Monitoring and Increasing Exercise Adherence in Older Adults by Robotic Intervention: A Proof of Concept Study. J. Robot. 2011, 2011, 1-11. [CrossRef]

26. Gorer, B.; Salah, A.A.; Akın, H.L. An autonomous robotic exercise tutor for elderly people. Auton. Robot. 2017, 41, 657-678. [CrossRef]

27. Kim, G.H.; Jeon, S.; Im, K.; Kwon, H.; Lee, B.H.; Kim, G.Y.; Jeong, H.; Han, N.E.; Seo, S.W.; Cho, H.; et al. Structural brain changes after traditional and robot-assisted multi-domain cognitive training in community-dwelling healthy elderly. PLoS ONE 2015, 10, e0123251. [CrossRef]

28. Fasola, J.; Matarić, M.J. A Socially Assistive Robot Exercise Coach for the Elderly. J. Hum. Robot. Interact. 2013, 2, 3-32. [CrossRef]

29. Pu, L.; Moyle, W.; Jones, C.; Todorovic, M. The Effectiveness of Social Robots for Older Adults: A Systematic Review and Meta-Analysis of Randomized Controlled Studies. Gerontologist 2019, 59, e37-e51. [CrossRef]

30. Zafrani, O.; Nimrod, G. Towards a Holistic Approach to Studying Human-Robot Interaction in Later Life. Gerontologist 2018, 59, e26-e36. [CrossRef] [PubMed]

31. Pedersen, I.; Reid, S.; Aspevig, K. Developing social robots for aging populations: A literature review of recent academic sources. Sociol. Compass 2018, 12, e12585. [CrossRef]

32. Kachouie, R.; Sedighadeli, S.; Khosla, R.; Chu, M.-T. Socially Assistive Robots in Elderly Care: A Mixed-Method Systematic Literature Review. Int. J. Hum. Comput. Interact. 2014, 30, 369-393. [CrossRef]

33. Alves-Oliveira, P.; Petisca, S.; Correia, F.; Maia, N.; Paiva, A. Social Robots for Older Adults: Framework of Activities for Aging in Place with Robots. In Social Robotics. ICSR 2015. Lecture Notes in Computer Science; Springer: Cham, Switzerland, 2015; pp. 11-20.

34. Wilson, G.; Pereyda, C.; Raghunath, N.; de la Cruz, G.; Goel, S.; Nesaei, S.; Minor, B.; Schmitter-Edgecombe, M.; Taylor, M.E.; Cook, D.J. Robot-enabled support of daily activities in smart home environments. Cogn. Syst. Res. 2019, 54, 258-272. [CrossRef] [PubMed]

35. Peleka, G.; Kargakos, A.; Skartados, E.; Kostavelis, I.; Giakoumis, D.; Sarantopoulos, I.; Doulgeri, Z.; Foukarakis, M.; Antona, M.; Hirche, S.; et al. RAMCIP_A Service Robot for MCI Patients at Home. In Proceedings of the 2018 IEEE/RSJ International Conference on Intelligent Robots and Systems (IROS), Madrid, Spain, 1-5 October 2018; pp. 1-9.

36. Fischinger, D.; Einramhof, P.; Papoutsakis, K.; Wohlkinger, W.; Mayer, P.; Panek, P.; Hofmann, S.; Koertner, T.; Weiss, A.; Argyros, A.; et al. Hobbit, a care robot supporting independent living at home: First prototype and lessons learned. Robot. Auton. Syst. 2016, 75, 60-78. [CrossRef]

37. Kostavelis, I.; Vasileiadis, M.; Skartados, E.; Kargakos, A.; Giakoumis, D.; Bouganis, C.-S.; Tzovaras, D. Understanding of Human Behavior with a Robotic Agent Through Daily Activity Analysis. Int. J. Soc. Robot. 2019, 11, 437-462. [CrossRef]

38. Honig, S.S.; Oron-Gilad, T.; Zaichyk, H.; Sarne-Fleischmann, V.; Olatunji, S.; Edan, Y. Toward Socially Aware Person-Following Robots. IEEE Trans. Cogn. Dev. Syst. 2018, 10, 936-954. [CrossRef]

39. Inagawa, M.; Takei, T.; Imanishi, E. Development of a Tower-type Cooking Robot. In Proceedings of the 2021 IEEE/SICE International Symposium on System Integration (SII), Iwaki, Fukushima, Japan, 11-14 January 2021; pp. 455-460.

40. Olatunji, S.; Markfeld, N.; Gutman, D.; Givati, S.; Sarne-Fleischmann, V.; Oron-Gilad, T.; Edan, Y. Improving the Interaction of Older Adults with a Socially Assistive Table Setting Robot. In Social Robotics. ICSR 2019. Lecture Notes in Computer Science; Springer: Cham, Swizterland, 2019; pp. 568-577.

41. Yin, J.; Apuroop, K.G.S.; Tamilselvam, Y.K.; Mohan, R.E.; Ramalingam, B.; Le, A.V. Table Cleaning Task by Human Support Robot Using Deep Learning Technique. Sensors 2020, 20, 1698. [CrossRef]

42. Jevtić, A.; Valle, A.F.; Alenyà, G.; Chance, G.; Caleb-Solly, P.; Dogramadzi, S.; Torras, C. Personalized Robot Assistant for Support in Dressing. IEEE Trans. Cogn. Dev. Syst. 2018, 11, 363-374. [CrossRef]

43. Canal, G.; Alenya, G.; Torras, C. Adapting robot task planning to user preferences: An assistive shoe dressing example. Auton. Robot. 2018, 43, 1343-1356. [CrossRef]

44. Liu, F.; Yu, H.; Wei, W.; Qin, C. I-feed: A robotic platform of an assistive feeding robot for the disabled elderly population. Technol. Health Care 2020, 28, 1-5. [CrossRef]

45. Park, D.; Hoshi, Y.; Mahajan, H.P.; Kim, H.K.; Erickson, Z.; Rogers, W.A.; Kemp, C.C. Active robot-assisted feeding with a general-purpose mobile manipulator: Design, evaluation, and lessons learned. Robot. Auton. Syst. 2020, 124, 103344. [CrossRef]

46. Zsiga, K.; Tóth, A.; Pilissy, T.; Péter, O.; Dénes, Z.; Fazekas, G. Evaluation of a companion robot based on field tests with single older adults in their homes. Assist. Technol. 2017, 30, 259-266. [CrossRef] [PubMed]

47. Jecker, N.S. You've got a friend in me: Sociable robots for older adults in an age of global pandemics. Ethic Inf. Technol. 2020, 1-9. [CrossRef] [PubMed]

48. Avioz-Sarig, O. Robotic System for Physical Training of Older Adults. Master's Thesis, Ben-Gurion University of the Negev, Beersheba, Israel, 2019.

49. Yuan, F.; Klavon, E.; Liu, Z.; Lopez, R.P.; Zhao, X. A Systematic Review of Robotic Rehabilitation for Cognitive Training. Front. Robot. AI 2021, 8, 1-24. [CrossRef]

50. Abdi, J.; Al-Hindawi, A.; Ng, T.; Vizcaychipi, M. Scoping review on the use of socially assistive robot technology in elderly care. BMJ Open 2018, 8, e018815. [CrossRef]

51. Matarić, M.J.; Scassellati, B. Socially Assistive Robotics. In Springer Handbook of Robotics; Springer Science and Business Media LLC: Cham, Switzerland, 2016; pp. 1973-1994. 
52. SBU. Methods of Promoting Physical Activity: A Systematic Review; Swedish Council on Health Technology Assessment in Health Care: Stockholm, Sweden, 2007.

53. Chase, J.-A.D. Interventions to Increase Physical Activity Among Older Adults: A Meta-Analysis. Gerontologist 2014, 55, 706-718. [CrossRef]

54. Csikszentmihalyi, M. Beyond Boredom and Anxiety: The Experience of Games in Work and Play; Jossey-Bass Inc.: San Francisco, CA, USA, 1975.

55. Deci, E.L.; Ryan, R.M. Intrinsic Motivation and Self-Determination in Human Behavior; Springer: New York, NY, USA, 1985.

56. Fasola, J.; Mataric, M.J. Using Socially Assistive Human-Robot Interaction to Motivate Physical Exercise for Older Adults. Proc. IEEE 2012, 100, 2512-2526. [CrossRef]

57. Avioz-Sarig, O.; Olatunji, S.; Sarne-Fleischmann, V.; Edan, Y. Robotic System for Physical Training of Older Adults. Int. J. Soc. Robot. 2020, 1-16. [CrossRef]

58. Heerink, M. Exploring the influence of age, gender, education and computer experience on robot acceptance by older adults. In Proceedings of the 6th International Conference on Human-Robot Interaction, Lausanne, Switzerland, 6-9 March 2011; pp. 147-148.

59. Giuliani, M.; Scopelliti, M.; Fornara, F. Elderly people at home: Technological help in everyday activities. In Proceedings of the IEEE International Workshop on Robot and Human Interactive Communication, Nashville, TN, USA, 13-15 August 2005; pp. 365-370. [CrossRef]

60. Louie, W.-Y.G.; McColl, D.; Nejat, G. Acceptance and Attitudes Toward a Human-like Socially Assistive Robot by Older Adults. Assist. Technol. 2014, 26, 140-150. [CrossRef] [PubMed]

61. Lapeyre, M.; Rouanet, P.; Oudeyer, P.-Y. The poppy humanoid robot: Leg design for biped locomotion. In Proceedings of the 2013 IEEE/RSJ International Conference on Intelligent Robots and Systems, Tokyo, Japan, 3-7 November 2013; pp. 349-356.

62. Devanne, M.; Nguyen, S.M. Multi-level motion analysis for physical exercises assessment in kinaesthetic rehabilitation. In Proceedings of the 2017 IEEE-RAS 17th International Conference on Humanoid Robotics (Humanoids), Birmingham, UK, 15-17 November 2017; pp. 529-534.

63. Taltal, S. A Computerized System for Measuring the Risk of Falls among the Elderly Through a Six-Meter Walking Test on a Narrow Path. Bachelor's Thesis, Ben-Gurion University of the Negev, Beersheba, Israel, 2021.

64. Vogel, T.; Brechat, P.-H.; Leprêtre, P.-M.; Kaltenbach, G.; Berthel, M.; Lonsdorfer, J. Health benefits of physical activity in older patients: A review. Int. J. Clin. Pract. 2009, 63, 303-320. [CrossRef]

65. Roy, N.; Baltus, G.; Fox, D.; Gemperle, F.; Goetz, J.; Hirsch, T.; Magaritis, D.; Montemerlo, M.; Pineau, J.; Roy, N.; et al. Towards Personal Service Robots for the Elderly. Work. Interact. Robot. Entertain. 2000, 25, 184.

66. Ezzati, A.; Katz, M.J.; Zammit, A.R.; Lipton, M.L.; Zimmerman, M.E.; Sliwinski, M.J.; Lipton, R.B. Differential association of left and right hippocampal volumes with verbal episodic and spatial memory in older adults. Neuropsychology 2016, 93, 380-385. [CrossRef]

67. Nacke, L.; Nacke, A.; Lindley, C. Brain Training for Silver Gamers: Effects of Age and Game Form on Effectiveness, Efficiency, Self-Assessment, and Gameplay Experience. CyberPsychol. Behav. 2009, 12, 493-499. [CrossRef]

68. Katz, J.E.; Halpern, D. Attitudes towards robots suitability for various jobs as affected robot appearance. Behav. Inf. Technol. 2013, 33, 941-953. [CrossRef]

69. Mullen, S.P.; Olson, A.E.; Phillips, S.M.; Szabo, A.N.; Wójcicki, T.R.; Mailey, E.L.; Gothe, N.P.; Fanning, J.T.; Kramer, A.; McAuley, E. Measuring enjoyment of physical activity in older adults: Invariance of the physical activity enjoyment scale (paces) across groups and time. Int. J. Behav. Nutr. Phys. Act. 2011, 8, 103. [CrossRef]

70. Davis, F.D. Perceived Usefulness, Perceived Ease of Use, and User Acceptance of Information Technology. MIS Q. 1989, 13, 319-340. [CrossRef]

71. Ma, Q.; Chan, A.H.; Chen, K. Personal and other factors affecting acceptance of smartphone technology by older Chinese adults. Appl. Ergon. 2016, 54, 62-71. [CrossRef] [PubMed]

72. Sundar, S.S.; Waddell, T.F.; Jung, E.H. The Hollywood Robot Syndrome media effects on older adults' attitudes toward robots and adoption intentions. In Proceedings of the 2016 11th ACM/IEEE International Conference on Human-Robot Interaction (HRI), Christchurch, New Zealand, 7-10 March 2016; pp. 343-350.

73. Sidaway, B.; Ala, B.; Baughman, K.; Glidden, J.; Cowie, S.; Peabody, A.; Roundy, D.; Spaulding, J.; Stephens, R.; Wright, D.L. Contextual Interference Can Facilitate Motor Learning in Older Adults and in Individuals with Parkinson's Disease. J. Mot. Behav. 2016, 48, 509-518. [CrossRef] [PubMed]

74. Kumar, S.; Itzhak, E.; Olatunji, S.; Sarne-Fleischmann, V.; Tractinsky, N.; Nimrod, G.; Edan, Y. Exploratory evaluation of politeness in human-robot interaction. arXiv 2021, arXiv:2103.08441.

75. Šabanović, S.; Chang, W.-L.; Bennett, C.C.; Piatt, J.A.; Hakken, D. A Robot of My Own: Participatory Design of Socially Assistive Robots for Independently Living Older Adults Diagnosed with Depression. In Human Aspects of IT for the Aged Population. Design for Aging. ITAP 2015. Lecture Notes in Computer Science; Springer: Cham, Switzerland, 2015; pp. 104-114.

76. Ostrowski, A.K.; DiPaola, D.; Partridge, E.; Park, H.W.; Breazeal, C. Older Adults Living with Social Robots: Promoting Social Connectedness in Long-Term Communities. IEEE Robot. Autom. Mag. 2019, 26, 59-70. [CrossRef] 